\title{
Utilization of Coagulation Studies in Emergency Department: A Chart Review
}

\author{
(1) Ahmad Wazzan ${ }^{1}$, (1) Abdulhadi Tashkandi² \\ 1Department of Emergency Medicine, King Saud Bin Abdulaziz University For Health Sciences, Jeddah, Saudi Arabia \\ 2Department of Emergency Medicine, Ministry of National Guard Health Affairs - King Abdulaziz Medical City, Jeddah, Saudi Arabia
}

\begin{abstract}
Aim: This study aimed to determine the prevalence of abnormal coagulation studies in emergency department (ED) patients with and to investigate the relationship among chief complaints, past medical history or drug history, and abnormal results of coagulation studies.

Materials and Methods: In this retrospective chart review study, ED records of patients who had undergone coagulation studies were obtained. Patient data, including demographics, chief complaints, past medical history, drug history, and clinical impression, were reviewed. Descriptive and statistical analyses were performed.

Results: A total of 322 charts were reviewed. Thirteen patients (4.04\%) had an abnormal international normalized ratio (INR), of which six (46.2\%) were on warfarin therapy. Although chest pain was the most prevalent chief complaint (10.4\%), no statistically significant relationship was found between chief complaints and INR levels. Patients with past medical history of thromboembolic risk were likely to have an abnormal INR [likelihood ratio (LR): 8.8]. Patients on warfarin therapy had a statistically significant likelihood of having abnormal INR (LR: 32.8) ( $p=0.000)$. Coagulation profiling was repeated in $4.35 \%$ of the patients, with a request gap mean of 6 days.

Conclusion: Chief complaints upon presentation to the ED are not good predictors of INR abnormalities. However, warfarin therapy and past medical history of thromboembolic events demonstrated robust association with abnormal INR levels. Routine coagulation studies are not indicated in all patients presenting to the ED.
\end{abstract}

Keywords: Coagulation, emergency department, utilization

\section{Introduction}

Emergency departments (EDs) use coagulation tests as part of their patients' evaluation. This would include a wide range of clinical scenarios where there is an anticipated possibility of performing an invasive procedure or initiating an anticoagulant or thrombolytic therapy. This is obviously done as a screening test for an unrecognized bleeding disorder or hypercoagulable state i.e. a baseline value.

Cost-effectiveness and patient satisfaction are two important factors that play a big role in health care management, particularly in the ED where waiting time and resources utilization are of a huge impact on the services provided. These two factors should be modified for the institutional benefit, patient care, and quality improvement. Proper utilization of certain laboratory tests plays a determinantal role in these factors. In our ED, 45,000 annual visits, the total number of coagulation profile requested in a single year was 8,695 . This represents $18.5 \%$ of total hematology tests and $7.2 \%$ of total laboratory investigations ordered throughout the same year.

The operational cost of the coagulation profile in the Kingdom of Saudi Arabia ranges from 18 to 37 US dollars.

Many studies showed a clear relationship between the patient length of stay in the ED, and laboratory performance and the number of tests requested per patient. Reduction in turnaround time affects emergency staff satisfaction as well $(1,2)$. Laboratory turn-around time for hematology requests from our department 
was ranging from 12 minutes to 665 minutes per sample. The average turn-around time was 75 minutes.

Many studies have evaluated the efficacy of routine coagulation studies, most of them in the surgical and anesthesia literature as preoperative screening tests (3). Additional studies evaluated their utility prior to angiographic tests, on admission to the general medicine ward, and one study evaluated their importance in patients with a probable diagnosis of deep vein thrombosis (4-6). None of these studies found any justification for routine administration of the tests in any of the abovementioned conditions. On the other hand, other studies showed the importance of Coagulation Profile as a prognostic factor in certain conditions e.g. polytrauma, head injuries, Systemic Inflammatory Response Syndrome, and Gastrointestinal bleeding (7-20).

\section{Materials and Methods}

Leaders of ED noticed that coagulation studies are being overutilized. A thorough literature review was done to find out that there are multiple studies that address the overutilization of the coagulation profile in other settings in the hospital.

The purpose of this study was to determine the prevalence of abnormal international normalized ratio (INR) levels in patients presenting to the ED and if there is a correlation between the INR levels and patients' chief complaints and other clinical data. The study was also quantifying the relevance and utilization of coagulation tests and its financial burden to the institution as well as the length of stay of patients in the ED, hence inconveniencing both the department and the patients.

In this retrospective chart review, we selected the month of August to apply our study to as it had the highest number of coagulation tests being requested throughout the year. The total number of ED visits during August was 3,579 patients.

We identified those patients who had a coagulation study done for, who were 801 patients. We postulated our margin of error to be $<5 \%$ which gave as a sample size of at least 260 . Using simple random sampling, we reviewed 322 charts of ED visits.

Data were entered through electronic sheets. Data collected were demographics, chief complaint, drug history "specifically aspirin, plavix, warfarin, and low molecular weight heparin (LMWH)", past medical history, clinical impression, and repeated tests if any. Some patients had more than one chief complaint; each chief complaint was counted as a separate entry. For statistical purposes, relevant chief complaints were grouped together and analyzed as one entity. All charts were included No patients were excluded from the study. For charts with missing "chief complaint" field, they were included in the "no history" category.
Other missing data were left blank during data entry. Past Medical History was categorized into groups of possible disease risk. These are; 1. Atherosclerotic Risk [diabetes mellitus (DM), hypertension (HTN), ischemic heart disease (IHD), cerebrovascular accidents (CVA) and dyslipidemias]; 2. Thrombo-embolic Risk [pulmonary embolism (PE), deep vein thrombosis (DVT), oncology patients]; 3. Respiratory Risk [chronic obstructive pulmonary diseases (COPD), bronchial asthma (BA), other pulmonary conditions]; 4. Other past medical histories. INR results were classified as normal and abnormal. Abnormal INR was defined as any INR $>1.5$.

\section{Statistical Analysis}

Linear Regression analysis of data was done using SPSS program version 15.0. This included descriptive data analysis and statistical data analysis for each variant versus INR. The study was done in accordance with the methods/methodical section of the Ethical Principles for Medical Research amended in October 2013. Statistical significance was defined at the $5 \%(p<0.05)$.

\section{Results}

Descriptive data analysis showed a wide range of Chief complaints for which coagulation studies are being requested (Table 1). The commonest chief complaint among patients who had a coagulation study requested was chest pain, followed by

\begin{tabular}{|l|l|l|}
\hline Table 1. Frequency of chief complaints & $\mathbf{n}$ & $\%$ \\
\hline Chief complaint & 41 & $10.4 \%$ \\
\hline Chest pain & 38 & $9.7 \%$ \\
\hline Abdominal pain & 31 & $7.9 \%$ \\
\hline Shortness of breath & 29 & $7.4 \%$ \\
\hline Other central nervous system complaints & 24 & $6.1 \%$ \\
\hline Other gastrointestinal complaints & 23 & $5.9 \%$ \\
\hline Vomiting & 23 & $5.9 \%$ \\
\hline Musculoskeletal pain & 23 & $5.9 \%$ \\
\hline Fever & 23 & $5.9 \%$ \\
\hline Obstetrics and gynecology & 23 & $5.9 \%$ \\
\hline Other complaints & 17 & $4.3 \%$ \\
\hline Limb(s) weakness & 16 & $4.1 \%$ \\
\hline No history & 16 & $4.1 \%$ \\
\hline Other cardiopulmonary complaints & 15 & $3.8 \%$ \\
\hline Dizziness & 14 & $3.6 \%$ \\
\hline Other abdominal pains & 12 & $3.1 \%$ \\
\hline Epigastric pain & 10 & $2.5 \%$ \\
\hline Motor vehicle accident & 8 & $2.0 \%$ \\
\hline Renal pain & 7 & $1.8 \%$ \\
\hline Head, eye, ear, nose or throat pain & & \\
\hline n: Number & & \\
\hline
\end{tabular}


abdominal pain and shortness of breath (10.4\%, 9.7\%, 7.9\%). Out of 322 INR results, 13 patient (4.04\%) had abnormal INR level, ranging from 1.6 to 5.6 with a mean of 2.7. These patients had different presenting chief complaints to the ED and variable past medical history (Tables 2 and 3). Among the patients with high INR levels, six patients were on warfarin (46.2\%), one of them was on aspirin as well. None of them was on plavix nor heparin/ LMWH (Table 4). One of the patients with abnormal INR had an INR level measured three days earlier. The first time showed a normal INR "1.2" while three days later it showed a high INR of 2.6. This patient was on Warfarin in both visits.

\begin{tabular}{|l|l|l|}
\hline \multicolumn{3}{|l|}{ Table 2. INR levels and their frequencies } \\
\hline INR & Frequency & Percentage \\
\hline$<1.5$ & 309 & $96.0 \%$ \\
\hline$>1.5$ & 13 & $4.0 \%$ \\
\hline Total & 322 & $100.0 \%$ \\
\hline INR: International normalized ratio \\
\hline
\end{tabular}

\begin{tabular}{|c|c|c|}
\hline Past medical history & $\mathrm{n}$ & $\%$ \\
\hline Hypertension & 80 & $25.7 \%$ \\
\hline Diabetes mellitus & 74 & $23.8 \%$ \\
\hline Ischemic heart disease & 45 & $14.5 \%$ \\
\hline Oncology & 30 & $9.6 \%$ \\
\hline Chronic obstructive pulmonary disease & 10 & $3.2 \%$ \\
\hline Cerebrovascular accident & 9 & $2.9 \%$ \\
\hline Bronchial asthma & 9 & $2.9 \%$ \\
\hline Other lung diseases & 6 & $1.9 \%$ \\
\hline Chronic liver disease & 6 & $1.9 \%$ \\
\hline Patient on active chemotherapy & 6 & $1.9 \%$ \\
\hline Thyroid disease & 6 & $1.9 \%$ \\
\hline Chronic renal failure & 5 & $1.6 \%$ \\
\hline Epilepsy & 5 & $1.6 \%$ \\
\hline Dyslipidemia & 4 & $1.3 \%$ \\
\hline Organ transplant & 4 & $1.3 \%$ \\
\hline Deep vein thrombosis & 3 & $1.0 \%$ \\
\hline Sickle cell anemia & 2 & $0.6 \%$ \\
\hline Psychiatric Illness & 2 & $0.6 \%$ \\
\hline Pulmonary embolism & 1 & $0.3 \%$ \\
\hline Pregnancy & 1 & $0.3 \%$ \\
\hline Other blood diseases & 1 & $0.3 \%$ \\
\hline Valvular heart disease & 1 & $0.3 \%$ \\
\hline Atrial fibrillation & 1 & $0.3 \%$ \\
\hline Total & 311 & $100.0 \%$ \\
\hline \multicolumn{3}{|l|}{ n: Number } \\
\hline
\end{tabular}

Coagulation studies were repeated for 14 patients on different presentations to the ED. Each patient had a repeated test twice with an interval ranging from 1 to 23 days, and a mean of 6 days. Table 5 is showing the INR values, chief complaints, and impression on each visit "if available". This is followed by the past medical history of the patient and his current medication.

No statistically significant relationship was found between any of the chief complaints and INR level (Table 6). Furthermore, no statistically significant relationship was found between past medical risk factors and INR levels (Table 5). On the other hand, there is a high statistical association between the use of warfarin and INR level (Table 7).

\section{Discussion}

The ED receives a wide range of clinical presentations. The situations in which patients present to the ED might influence the clinical course of the patient including history taking, physical examination, laboratory investigations, Interventions, type of medications, and patient disposition. Another practical obstacle is patient with difficult intravenous access e.g. children and IV drug abusers.

The initial chief complaint upon presenting to the ED might not be the complaint of concern to the attending physician e.g. a patient who comes with leg pain who is found to be on warfarin therapy for DVT and having an associated dyspnea.

\begin{tabular}{|l|l|l|l|}
\hline \multicolumn{3}{|l|}{ Table 4. Clinical data of patients with abnormal INR level } \\
\hline INR & Chief complaint & $\begin{array}{l}\text { Past medical } \\
\text { history }\end{array}$ & Warfarin \\
\hline 5.6 & $\begin{array}{l}\text { Generalized body } \\
\text { weakness }\end{array}$ & PE, oncology & Yes \\
\hline 4.2 & Dizziness & IHD & Yes and ASA \\
\hline 3.7 & Palpitation, fever & HTN, IHD, COPD & Yes \\
\hline 3.1 & $\begin{array}{l}\text { Chest pain, shortness of } \\
\text { breath }\end{array}$ & DM, HTN, IHD, BA & Yes \\
\hline 2.6 & Chest pain & DM, HTN, IHD & Yes \\
\hline 2.4 & Ear discharge, fever & No & No \\
\hline 2.4 & Sore throat & DM, HTN, DVT & Yes \\
\hline 2.1 & Right sided weakness & DM, HTN & No \\
\hline 2.0 & Decreased urine output & DM, HTN & No \\
\hline 1.9 & Left leg pain & DVT & No \\
\hline 1.8 & Chest pain & DM, HTN, IHD & No \\
\hline 1.7 & Motor vehicle accident & No & No \\
\hline 1.6 & Shortness of breath & Oncology & No \\
\hline $\begin{array}{l}\text { INR: International normalized ratio, PE: Pulmonary embolism, IHD: Ischemic } \\
\text { heart disease, HTN: Hypertension, COPD: Chronic obstructive pulmonary disease, } \\
\text { DM: Diabetes mellitus, BA: Bronchial asthma, DVT: Deep vein thrombosis, ASA: } \\
\text { American Society of Anesthesiologists }\end{array}$ & \\
\hline
\end{tabular}




\begin{tabular}{|l|l|}
\hline $\begin{array}{l}\text { Table 5. The likelihood ratio of abnormal INR vs historical risk } \\
\text { factors }\end{array}$ & Likelihood ratio (p value) \\
\hline Risk factors & $7.0(0.07)$ \\
\hline Atherosclerosis & $8.8(0.01)$ \\
\hline Thromboembolic & $4.7(0.10)$ \\
\hline Lung & $3.4(0.06)$ \\
\hline Other & \\
\hline INR: International normalized ratio &
\end{tabular}

\begin{tabular}{|c|c|c|}
\hline Chief complaint & $\begin{array}{l}\text { Odds ratio }(95 \% \\
\mathrm{CI})\end{array}$ & $\begin{array}{l}\text { Likelihood ratio } \\
\text { ( } \mathrm{p} \text { value) }\end{array}$ \\
\hline Musculoskeletal pain & $1.09(0.14-8.75)$ & $0.01(0.94)$ \\
\hline Other complaints & $1.14(0.14-9.22)$ & $0.02(0.90)$ \\
\hline Limb(s) weakness & $1.53(0.19-12.48)$ & $0.14(0.71)$ \\
\hline Shortness of breath & $1.76(0.37-8.31)$ & $0.45(0.50)$ \\
\hline Dizziness & $1.76(0.21-14.47)$ & $0.24(0.63)$ \\
\hline Chest pain & $2.14(0.56-8.12)$ & $1.10(0.30)$ \\
\hline Fever & $2.49(0.52-11.99)$ & $1.08(0.30)$ \\
\hline Motor vehicle accident & $2.78(0.33-23.73)$ & $0.69(0.41)$ \\
\hline Renal pain & $3.60(0.41-31.59)$ & $1.01(0.32)$ \\
\hline Cardiac complaint & $6.83(1.68-27.83)$ & $5.39(0.02)$ \\
\hline $\begin{array}{l}\text { Head, eye, ear, nose and } \\
\text { throat complaint }\end{array}$ & $\begin{array}{l}11.06 \\
(1.93-63.40)\end{array}$ & $5.13(0.02)$ \\
\hline Abdominal pain & $N / A^{*}$ & $3.34(0.07)$ \\
\hline Vomiting & $N / A^{*}$ & $1.97(0.16)$ \\
\hline $\begin{array}{l}\text { Other gastrointestinal } \\
\text { complaints }\end{array}$ & $N / A^{*}$ & $1.88(0.17)$ \\
\hline Other abdominal pain & $N / A^{*}$ & $1.18(0.28)$ \\
\hline $\begin{array}{l}\text { Obstetrics and } \\
\text { gynecological complaint }\end{array}$ & $N / A^{*}$ & $1.97(0.16)$ \\
\hline No history & $N / A^{*}$ & $1.35(0.25)$ \\
\hline Epigastric pain & $N / A^{*}$ & $1.01(0.32)$ \\
\hline Central nervous system & $N / A^{*}$ & $2.51(0.11)$ \\
\hline
\end{tabular}

\begin{tabular}{|c|c|c|}
\hline Rx & Odds ratio $(95 \% \mathrm{Cl})$ & LR ( $p$ value) \\
\hline Warfarin & $131.6(22.5-770.1)$ & $32.8(0)$ \\
\hline ASA & $1.4(0.2-11.7)$ & $0.1(0.8)$ \\
\hline Plavix & N/A & $0.7(0.4)$ \\
\hline
\end{tabular}

INR: International normalized ratio, LR: Likelihood ratio, CI: Confidence interval, ASA: American Society of Anesthesiologists, N/A: Not available
Another point worth mentioning is, "pricking the patient a second time". Many physicians would do a coagulation profile to keep it "stand by" or "if needed" rather than a second prick. This is understandable as many patients in ED would have a disposition diagnosis different from their provisional diagnosis. The ethical and cost-effectiveness aspects should be balanced to reach an answer to the question "Prick again or not?". Further studies should evaluate these aspects and how to implement it.

\section{Study Limitations}

Our study had the limitations of small sample size, limited financial resources, time limitation.

Despite the major downside of our study i.e. sample size, our study is enforced by the similar results found in the literature.

\section{Conclusion}

EDs should develop protocols, guidelines or recommendations to improve the utilization of coagulation profile. This was found cost-effective (21-25). These guidelines should be flexible to adopt a wide range of clinical presentations to ED. Other studies have shown that obtaining a history of previous bleeding, liver disease or therapy with anticoagulants is a better predictor of abnormal coagulation profile or significant bleeding tendency (26-31).

Other authors recommend initiation of thrombolytic therapy in ischemic stroke or ST-elevation myocardial infarction, without waiting for coagulation studies results. In these studies, abnormal levels were predictable by history alone $(3,32,33)$. Invasive procedures in the ED can be done without a baseline INR, provided that clinical information ruled out the possibility of bleeding tendency (34-36).

\section{Ethics}

Ethics Committee Approval: Since this retrospective study conducted before January 2020, and ethics committee approval was not necessary in that time, ethics committee approval was not obtained.

Informed Consent: Retrospective study.

Peer-review: Externally peer-reviewed.

\section{Authorship Contributions}

Concept: A.W., A.T., Design: A.W., A.T., Data Collection or Processing: A.W., A.T., Analysis or Interpretation: A.W., A.T., Literature Search: A.W., A.T., Writing: A.W., A.T.

Conflict of Interest: No conflict of interest was declared by the authors. 
Financial Disclosure: The authors declared that this study received no financial support.

\section{References}

1. Steindel SJ, Howanitz PJ. Physician satisfaction and emergency department laboratory test turnaround time. Arch Pathol Lab Med. 2001;125:863-71.

2. Holland LL, Smith LL, Blick KE. Reducing laboratory turnaround time outliers can reduce emergency department patient length of stay. Am J Clin Pathol. 2005; $124: 672-4$

3. Schwartz D. Utility of routine coagulation studies in emergency department patients with suspected acute coronary syndromes. Isr Med Assoc J. 2005;7:502-6.

4. Darcy MD, Kanterman RY, Kleinhoffer MA, Vesely TM, Picus D, Pilgram TK. Evaluation of coagulation tests as predictors of angiographic bleeding complications. Radiology. 1996;198:741-4.

5. Hubbell FA, Frye EB, Akin BV, Rucker L. Routine admission laboratory testing for general medical patients. Med Care. 1988;26:619-30.

6. McKinley L, Wrenn K. Are baseline prothrombin time/partial thromboplastin time values necessary before instituting anticoagulation? Ann Emerg Med. 1993;22:697-702.

7. Mikhail J. The trauma triad of death: hypothermia, acidosis, and coagulopathy. AACN Clin Issues. 1999;10:85-94.

8. LoVecchio F, Pizon AF, Berrett C, Balls A. Outcomes after environmental hyperthermia. Am J Emerg Med. 2007;25:442-4.

9. Henzler D, Cooper DJ, Mason K. Factors contributing to fatal outcome of traumatic brain injury: a pilot case study. Crit Care Resusc. 2001;3:153-7.

10. Liu YG, Li CS. Coagulation dysfunctions in patients with systemic inflammatory response syndrome. Zhonghua Nei Ke Za Zhi. 2004;43:94-7.

11. Schreyer N, Engeler A, Leyvraz PF. [10 years experience in surgical resuscitation at a university hospital center. Determination of a criterion for identifying patients at risk for fatal irreversible coagulopathy]. Swiss Surg. 2003;9:16772.

12. Holmes JF, Goodwin HC, Land C, Kuppermann N. Coagulation testing in pediatric blunt trauma patients. Pediatr Emerg Care. 2001;17:324-8.

13. Kanich W, Brady WJ, Huff JS, Perron AD, Holstege C, Linbeck G, et al. Altered mental status: evaluation and etiology in the ED. Am J Emerg Med. 2002;20:613-7.

14. Wang TL, Jang TN, Huang CH, Kao SJ, Lin CM, Lee FN, et al. Establishing a clinical decision rule of severe acute respiratory syndrome at the emergency department. Ann Emerg Med. 2004;43:17-22.

15. Kollef MH, O'Brien JD, Zuckerman GR, Shannon W. BLEED: A classification tool to predict outcomes in patients with acute upper and lower gastrointestinal hemorrhage. Crit Care Med. 1997;25:1125-32.

16. Popović N, Blagojević Z, Nikolić V, Arsenijević LJ, Karamarković A, Stefanović $B$, et al. Massive hemorrhage and mechanisms of coagulopathy in trauma. Acta Chir lugosl. 2006;53:89-92.

17. Brooks JP, Marshall JH. Early awareness of post-traumatic coagulopathy. Injury. 1995;26:283-4.

18. Solenski NJ. Transient ischemic attacks: Part I. Diagnosis and evaluation. Am Fam Physician. 2004;69:1665-74.
19. Fabbri A, Servadei F, Marchesini G, Stein SC, Vandelli A. Early predictors of unfavorable outcome in subjects with moderate head injury in the emergency department. J Neurol Neurosurg Psychiatry. 2008;79:567-73.

20. Nuevo González JA, Ballesteros JCC, Holguín EP, Saro BB, Soler EV, Fernández JAS. Oral anticoagulation excess: analysis from an emergency department. Rev Clin Esp. 2008;208:66-70.

21. Groopman DS, Powers RD. Effect of "standard order" deletion on emergency department coagulation profile use. Ann Emerg Med. 1992;21:524-7.

22. Sucov A, Bazarian JJ, deLahunta EA, Spillane L. Test ordering guidelines can alter ordering patterns in an academic emergency department. J Emerg Med. 1999;17:391-7.

23. Auble TE, Taylor DM, Hsu EB, Yealy DM. Evaluation of guidelines for ordering prothrombin and partial thromboplastin times. Acad Emerg Med. 2002;9:567-74.

24. Barnes D. Coagulation tests in the emergency department. Aust Clin Rev. 1991;11:116.

25. Peterson P, Hayes TE, Arkin CF, Bovill EG, Fairweather RB, Rock WA Jr, et al. The preoperative bleeding time test lacks clinical benefit: College of American Pathologists' and American Society of Clinical Pathologists' position article. Arch Surg. 1998;133:134-9.

26. Kitchens CS. Preoperative PTs, PTTs, cost-effectiveness, and health care reform. Radical changes that make good sense. Chest. 1994;106:661-2.

27. Sramek A, Eikenboom JC, Briet E, Vandenbroucke JP, Rosendaal FR. Usefulness of patient interview in bleeding disorders. Arch Intern Med. 1995;155:140915.

28. Awan MS, Iqbal M, Imam SZ. Epistaxis: when are coagulation studies justified?. Emerg Med J. 2008;25:156-7.

29. Dizdar O, Onal IK, Ozakin E, Karakilic E, Karadag O, Kalyoncu U, et al. Research for the bleeding tendency in patients presenting with significant epistaxis. Blood Coagul Fibrinolysis. 2007;18:41-3.

30. Singer AJ, Blanda M, Cronin K, Khwaja-LoGiudice M, Gulla J, Bradshaw J, et al. Comparison of nasal tampons for the treatment of epistaxis in the emergency department: a randomized controlled trial. Ann Emerg Med. 2005;45:134-9.

31. Newman DH, Zhitomirsky I. The prevalence of nontherapeutic and dangerous international normalized ratios among patients receiving warfarin in the emergency department. Ann Emerg Med. 2006;48:182-9, 189.e1.

32. Gottesman RF, Alt J, Wityk RJ, Llinas RH. Predicting abnormal coagulation in ischemic stroke: reducing delay in rt-PA use. Neurology. 2006;67:1665-7.

33. Derhaschnig U, Laggner AN, Röggla M, Hirschl MM, Kapiotis S, Marsik C, et al. Evaluation of coagulation markers for early diagnosis of acute coronary syndromes in the emergency room. Clin Chem. 2002;48:1924-30.

34. Lin CH, Shih FY, Ma MHM, Chiang WC, Yang CW, Ko PCI. Should bleeding tendency deter abdominal paracentesis? Dig Liver Dis. 2005;37:946-51.

35. O'Connor RE, Feldstein JS, Bouzoukis JK. Thoracentesis in the emergency department. J Emerg Med. 1985;2:433-42.

36. Innes GD, Dillon EC, Holmes A. Low-molecular-weight heparin in the emergency department treatment of venous thromboembolism. J Emerg Med. 1997;15:563-6. 